WellBeing International

WBI Studies Repository

2002

\title{
Convergence of Complex Cognitive Abilities in Cetaceans and Primates
}

Lori Marino

Emory University

Follow this and additional works at: https://www.wellbeingintlstudiesrepository.org/acwp_asie

Part of the Animal Studies Commons, Comparative Psychology Commons, and the Other Animal Sciences Commons

\section{Recommended Citation}

Marino, L. (2002). Convergence of complex cognitive abilities in cetaceans and primates. Brain Behavior and Evolution, 59(1-2), 21-32.

This material is brought to you for free and open access by WellBeing International. It has been accepted for inclusion by an authorized administrator of the WBI Studies Repository. For more information, please contact wbisr-info@wellbeingintl.org.

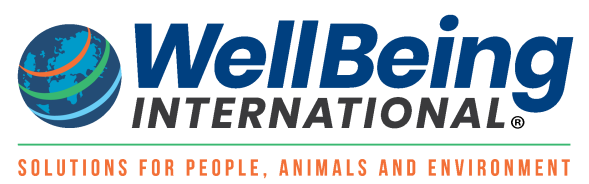




\title{
Convergence of Complex Cognitive Abilities in Cetaceans and Primates
}

\author{
Lori Marino \\ Emory University
}

\section{KEYWORDS}

Convergence, intelligence, cetacean, primate, mammal

\begin{abstract}
What examples of convergence in higher-level complex cognitive characteristics exist in the animal kingdom? In this paper I will provide evidence that convergent intelligence has occurred in two distantly related mammalian taxa. One of these is the order Cetacea (dolphins, whales and porpoises) and the other is our own order Primates, and in particular the suborder anthropoid primates (monkeys, apes, and humans). Despite a deep evolutionary divergence, adaptation to physically dissimilar environments, and very different neuroanatomical organization, some primates and cetaceans show striking convergence in social behavior, artificial 'language' comprehension, and self-recognition ability. Taken together, these findings have important implications for understanding the generality and specificity of those processes that underlie cognition in different species and the nature of the evolution of intelligence.
\end{abstract}

\section{Introduction}

In his popular 1983 article 'The Wisdom of Casey Stengel' Stephen Jay Gould posed the following questions: If we could start the earth's tape anew, would intelligent creatures again evolve? If other worlds share our basic chemistry and conditions, has intelligence arisen on them [Gould, 1983]? These inquiries embody the question of whether attributes that we would identify as intelligence on a par with humans can arise independently of human evolution. At the core of this question is the phenomenon of convergent intelligence.

Convergence is a process by which similarity between species occurs because of adaptation to similar environmental pressures and, by definition, not because of phylogenetic relatedness (homology). Convergence is one kind of homoplasy. The others are parallelism and reversal. Convergent traits are defined as those that evolved independently (with the implicit acknowledgement that, as far as we know, no two groups on Earth are completely independent because all life evolved from a single ancestor). Convergence is also often used as a synonym for analogy, i.e. a similar character in two species that was not present in their common ancestor [Ridley, 1993]. The greater the phylogenetic separation of the two groups the stronger the case for convergence.

Convergent evolution is a process that takes place on many levels. The convergent evolution of flight is a superb example of convergence of function without convergence of structure. Bats, insects and birds, as well as the extinct flying reptiles all evolved the capacity for active flight. Yet none of these groups are closely related. All have long separate evolutionary histories and use very different mechanisms for 
achieving the same behavioral outcome - powered flight. The wing of a bird is not very similar to the wing of an insect or a bat, for instance.

Convergence can also occur when two species not only independently evolve the same function, but also the same underlying structural or mechanistic basis for that function. This level of convergence is exemplified by recent findings that two very distantly related groups of marine mammals, whales and seals, have developed the same form of short wavelength color blindness through the same route, that is, specific loss of S-opsin cones in the retina [Peichl et al., 2001]. This particular form of colorblindness, the authors postulate, might be adaptive to coastal species of marine mammals.

The two previous examples of convergence reveal that convergence can occur on a functional level without complete structural convergence (active flight accomplished by different 'wing mechanisms'). Convergence can also occur in structure as well as function, as when color blindness is underwritten by the same physiological mechanism. The fact that convergence may occur at both or just one of these levels is particularly relevant to the forthcoming discussion about convergence of intelligence.

There are abundant examples in nature of both structural and functional convergence in morphology, physiology, and simple behaviors. But what examples of convergence in higher-level complex cognitive characteristics, vis-a-vis, Gould's convergent intelligence, exist? In this paper I will provide evidence that convergent intelligence has occurred in two distantly related mammalian taxa. One of these is the order Cetacea (dolphins, whales and porpoises) and the other is the order Primates and, in particular, the suborder anthropoid primates (monkeys, apes, and humans). The focus on this comparison does not imply that convergence in complex cognitive characteristics has occurred only in cetaceans and primates. However, given our own species' status as a primate and given the emphasis on 'intelligence on a par with humans' in questions such as the ones posed by Gould, I argue that primate-cetacean comparisons are particularly relevant to the question of convergence in intelligence. In this paper I will (1) discuss how cetaceans and primates meet the criteria for convergence, (2) present examples of convergence in complex behaviors and cognitive abilities in these two groups, and (3) discuss the implications of this evidence for the evolution of intelligence in general.

\section{Separate Evolutionary Histories and Divergent Brain Organization}

One of the defining criteria of convergence is that it occurs in groups that are not closely related to each other. Therefore, phylogenetic proximity must be essentially ruled out (despite its continuous nature) for a trait to be considered convergent across two or more groups. The case of primates and cetaceans represents one of the deepest phylogenetic divergences among the mammals.

There are two living suborders of Primates: Prosimii (prosimians) and Anthropoidea (monkeys, apes, and hominids). The Anthropoids are the focal primate group in this paper. The earliest primates emerged in the fossil record from an insectivore-like mammal during the late Cretaceous Period between 65 and 70 million years ago (mya). These early small shrew-like animals, identified collectively as Purgatorius, were followed by a highly successful group of archaic primate-like mammals that flourished in the Paleocene and early Eocene epochs, i.e., between 50 and 65 mya. Prosimians, the first undisputed primates, emerged during the early Eocene epoch. Monkeys evolved from a group of prosimians in the very early Oligocene epoch about 37-40 mya. The first primitive apes from which the hominoids (lesser apes, great apes and hominids) evolved appear in the fossil record from around 20-25 mya in the early Miocene epoch. The evolutionary divergence among all of the existing great apes and humans occurred in the last 15 million years. The chimpanzee-hominid split occurred approximately 6 mya and the divergence between bonobos (pygmy chimpanzees) and common chimpanzees occurred as recently as 2.5 mya [Napier and Napier, 1985; Fleagle, 1988]. 
Cetacea include the two living suborders Odontoceti (dolphins, toothed whales, and porpoises) and Mysticeti (baleen and rorqual whales) and one extinct archaic suborder from the Eocene referred to as Archaeoceti. Cetaceans originated when a hoofed Paleocene land mammal adopted an aquatic lifestyle between 55-60 mya (late Paleocene-early Eocene) and gave rise to the archaeocetes. Archaeocetes radiated into several forms in the Eocene epoch, but were extinct as a group by the beginning of the Oligocene epoch, 37 mya. The earliest odontocetes and mysticetes first appeared in the fossil record at about the same time that the last archaeocetes disappeared. Early modern cetacean species appeared in the fossil record by the mid Miocene epoch and most modern species were established by the onset of the Pleistocene, i.e., 5 mya ago [Barnes et al., 1985; Fordyce and Barnes, 1994; Bajpai and Gingerich, 1998; Thewissen, 1998].

Fig. 1. Illustration of the phylogenetic relationships among several major living primate and cetacean groups and their estimated time of divergence. Mya = million years ago.

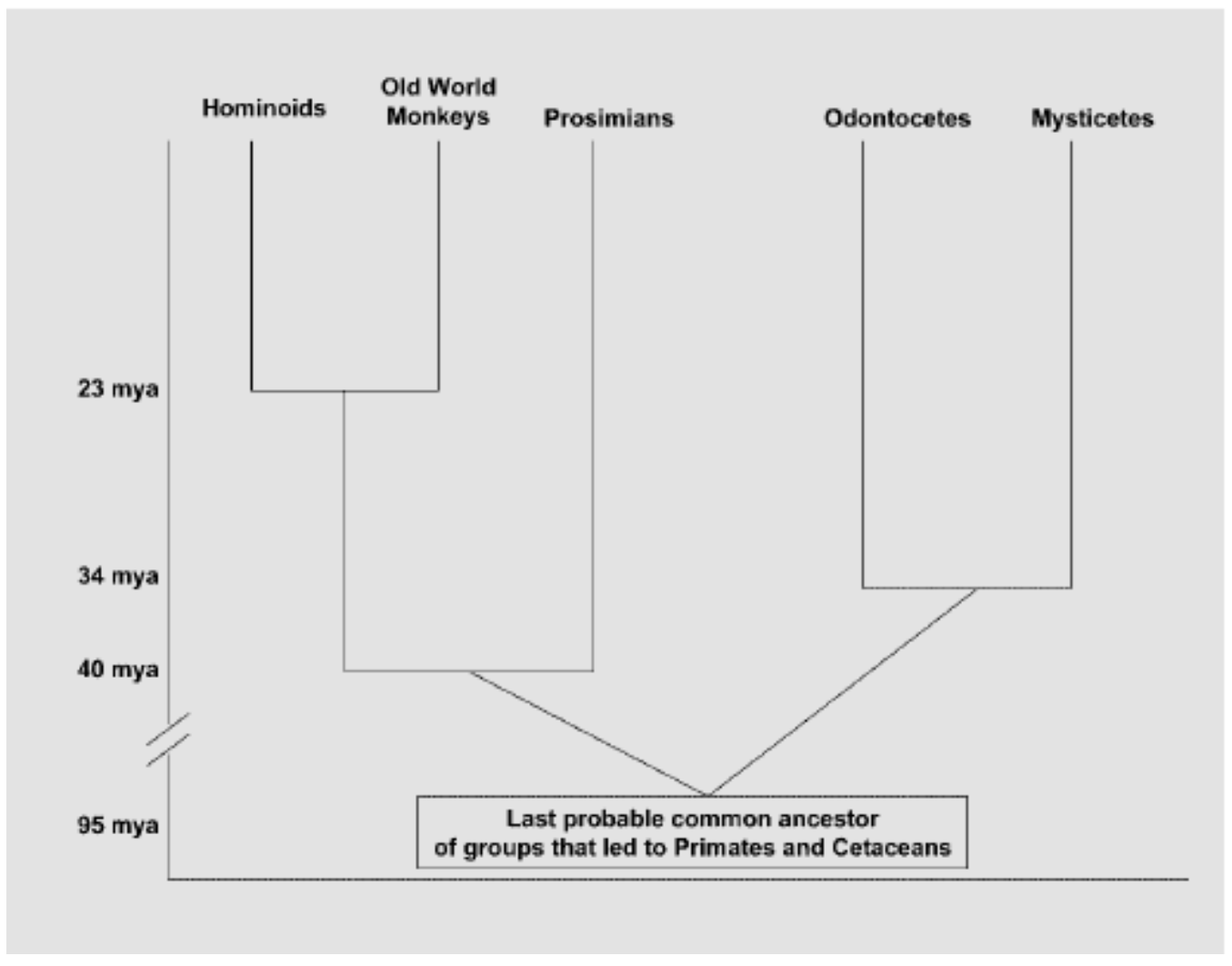

It is clear from the fossil record that the divergence between cetaceans and primates had already occurred at least 65 mya. However, the divergence between the ancestral mammal groups that eventually led to cetaceans and to primates probably occurred even earlier in the Mesozoic Era 90-95 mya [Cooper et al., 1990; Bromham et al., 1999] although the mammalian fossil record becomes increasingly sparse the further back in time. Figure 1 shows the phylogenetic relationships among major living primate and cetacean groups and the estimated time of their divergence.

During their long independent evolutionary histories primates and cetaceans adapted to radically different physical requirements (arboreal/terrestrial and aquatic, respectively) that led to pronounced differences in body shape and physiology between the two groups. But the differences that reflect the evolution of intelligence are found in brain morphology and function. Although these differences are less obvious than 
other physical differences between cetaceans and primates, e.g., fins versus hands, the differences in brain anatomy are arguably among the most striking differences between the two groups and have the most profound implications for studies of comparative intelligence.

Compared with many other mammalian brains, and particularly primate brains, cetacean brain morphology is unusual in many respects. Cetacean brains and primate brains are characterized by different elaborative or 'leading edge' trends. Referring to the way in which brain tissue has expanded in dolphins Morgane et al. state that '...the lobular formations in the dolphin brain are organized in a pattern fundamentally different from that seen in the brains of primates or carnivores' [Morgane et al., 1980, pp. 105].

The differences between primate and cetacean brains are visually striking at the gross morphological level (see fig. 2). The cetacean brain shows a proliferation of tissue along the lateral axis in the 'temporal' and 'parietal' regions [Morgane et al., 1980; Ridgway, 1990]. The primate brain, on the other hand, is characterized by major augmentation along the frontal - occipital axis. A particularly relevant feature of primate (and particularly human) brains is the large frontal lobe which is elaborated in most primates relative to other mammals. The expansion of the frontal lobes in great apes and humans and a body of literature on the effects of frontal lobe damage in humans and nonhuman primates have formed the basis for the continuing focus upon the frontal lobes, and particularly the prefrontal cortex, as the neurological substrate for complex executive functions, including self-awareness [Gallup, 1998; Grossman and Desposito, 1996; Keenan et al., 2000; Rowe et al., 2001; Stone et al., 1998; Stuss, 1991; Stuss et al., 2001]. In contrast, the cetacean brain evinces no elaboration of the frontal region. In fact the diminutive frontal cortical region in cetacean brains has prompted some investigators to relabel the anterior region of the cetacean brain with the term 'orbital' lobe [Morgane et al., 1980]. This difference in the degree of frontal cortical elaboration between primates and cetaceans is a pivotal point around which the relevance of finding self-recognition in dolphins (discussed later) revolves.

Fig. 2. Human (Homo sapiens) and bottlenose dolphin (Tursiops truncatus) brains. Images courtesy of the Comparative Mammalian Brain Collection, The National Museum Of Health and Medicine, Armed Forces Institute of Pathology, Washington, D.C.
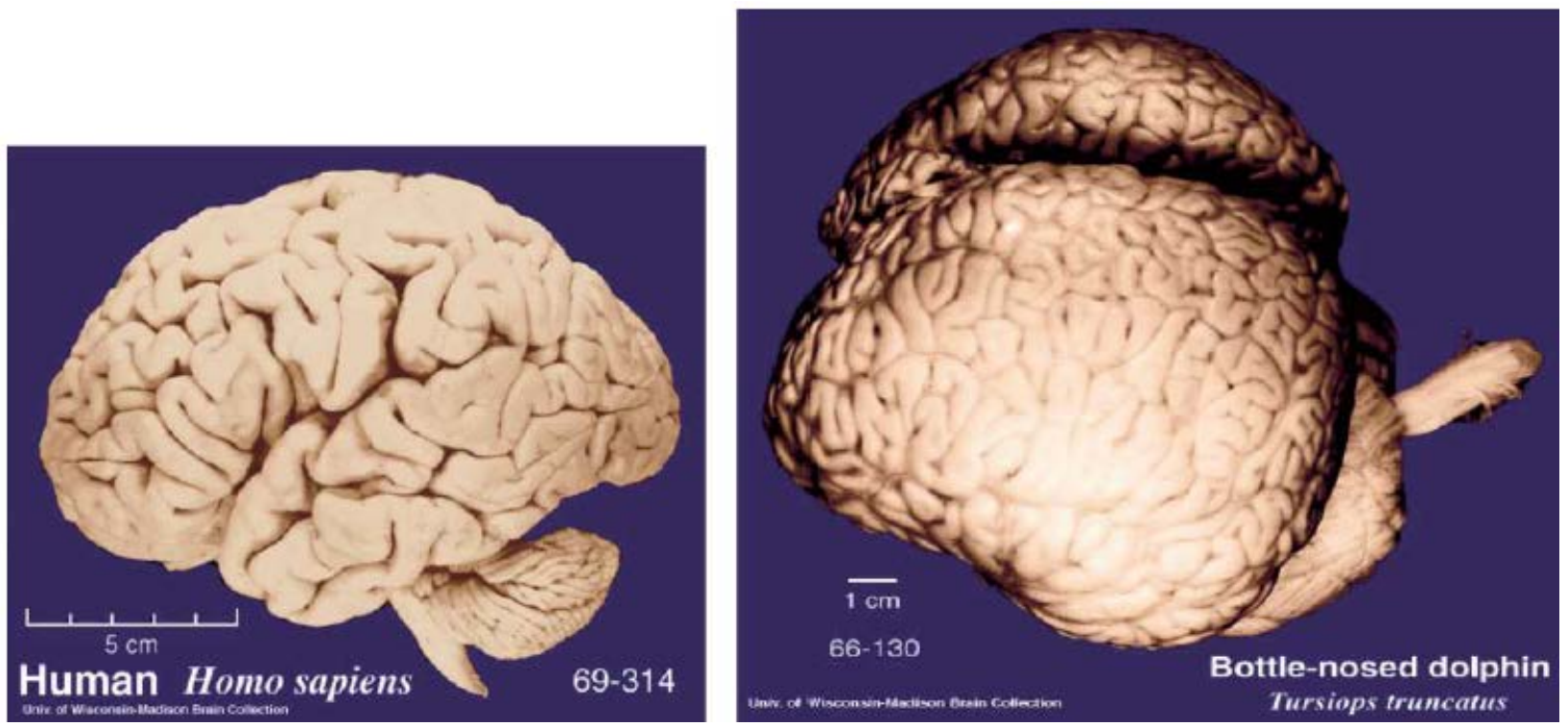
Furthermore, whereas the primate brain is patterned into three contiguous lobes: rhinic, limbic, and supralimbic, the cetacean brain is organized around three distinct concentric tiers of tissue that include the limbic and supralimbic but also an entirely unique paralimbic region, the function of which is largely unknown. The segregation of the limbic and supralimbic regions by an interposed paralimbic lobe is a radical departure from the typical terrestrial mammalian pattern of cortical evolution [Morgane et al., 1980].

The fundamental topography of cortical sensory projection regions in the cetacean brain also stands in stark contrast to that of primates. In primates, visual and auditory projection zones are located in the occipital and temporal lobes, respectively [Davis, 1997]. These areas are interposed by extensive nonprojection or 'association' regions that involve more integrated levels of information processing. In cetaceans, the major projection zones exhibit an entirely different pattern of localization than in primates. (Although these findings are based on studies with just a few odontocete species, e.g., the bottlenose dolphin or the harbor porpoise, for the purposes of the present argument the general term 'cetacean' or 'dolphin' will be used with the implicit assumption that there are differences across cetacean species but also common trends that can be characterized as generally 'cetacean' in nature. An analogous assumption is made when using the term 'primate'.) Visual sensory zones in cetaceans are found throughout the lateral gyrus and down the banks of the interhemispheric cleft. Large primary and secondary auditory projection zones occupy the neighboring gyri just lateral to the visual region. This highly unusual arrangement of cortical functional zones in cetaceans is made even more atypical by a pattern of 'cortical adjacency' whereby the unimodal visual and auditory projection zones adjoin each other without intervening associative regions. A vast expanse of nonprojectional cortex of unknown function surrounds the primary and secondary projection zones in the cetacean brain [Sokolov et al., 1972; Ladygina et al., 1978; Supin et al., 1978; Popov et al., 1986].

In addition to an unusual cortical arrangement of sensory zones the cetacean brain is characterized by an unusually high degree of interhemispheric independence relative to other mammals. Moreover, dolphins evince unihemispheric sleep and appear to lack a Rapid-Eye- Movement (REM) stage of sleep during which, in primates, dreaming occurs [Mukhametov, 1984].

The differences in gross morphology and topological arrangement of cortical sensory zones between cetacean and primate brains persist at an even deeper level in the form of profound differences in cortical cytoarchitecture. Primate neocortex is characterized by six heterogeneous layers, including the internal granular layer IV, which receives topographically organized sensory inputs from the thalamus and also contains interneuronal connections [Kandel et al., 1991; Allman, 1999]. Cetacean neocortex, in contrast, is thinner than typical primate neocortex because it contains only five identifiable layers. Layer IV is absent or extremely sparse in adult dolphins. (An identifiable granular layer IV is reported to exist in fetal and neonatal bottlenose dolphin cortex but disappears by a very early juvenile age [Garey et al., 1985; Garey and Leuba, 1986]. If these findings are robust they suggest that a neocortical granular layer IV is a regressive character in cetaceans.) Additionally, the cetacean cortex appears to be made up of a narrower range of cell types than the primate neocortex [Glezer et al., 1988]. Primate neocortical evolution is characterized by both an increase in mass (multiplication of cortical units) and an increase in heterogeneity or structural differentiation. In contrast, cetacean neocortex has expanded immensely but without as much of an increase in cellular differentiation. Therefore, primate and cetacean brains possess different 'leading edge' characteristics. Primate neocortical evolution appears to have occurred through both substantial modification of modular units and multiplication of those units, resulting in a significant degree of cortical heterogeneity as well as sheer volume. On the other hand, cetacean neocortical evolution appears to have taken place with little columnar modification and a more substantial increase in comparatively less modified modules. This process may account for the relative homogeneity coupled 
with the extremely large surface area of the cetacean neocortex [Glezer et al., 1988]. These differences in the features of the primate and cetacean neocortex have compelled several investigators to view the cetacean neocortex as representative of an entirely different mode of cortical elaboration from other mammals [Glezer et al., 1988].

Primate and cetacean brains, therefore, represent two fundamentally different cortical organizational themes. The existence of possibly two divergent modes of neocortical elaboration in primates and cetaceans compels the conclusion that any similar complex cognitive processes between primates and cetaceans are convergent.

\section{Convergences in Cetaceans and Primates}

\section{Encephalization}

Despite striking differences in neuroanatomical organization, particularly regarding neocortical arrangement and cytoarchitecture, cetaceans and primates have apparently undergone similar pressures for increased brain mass in their evolutionary history. Brain size evolution, or encephalization, can be quantitatively expressed as an Encephalization Quotient (EQ) [Jerison, 1973], which is a measure of observed brain size relative to expected brain size derived from a regression of brain weight on body weight for a sample of species. EQ values of one, less than one, and greater than one indicate a relative brain size that is average, below average, and above average, respectively.

Although there is a range of encephalization levels within cetaceans and primates, as there is in any taxonomic group, the highest levels of encephalization in the animal kingdom are possessed by cetacean and primate species [Marino, 1998]. Specifically, within the primate order, modern humans, extinct hominids, great apes, and some monkeys are characterized by extremely high EQ values. The EQ value for modern humans is 7.0 [Marino, 1998]. EQs have been estimated to range from 2.5 to 7.5 for fossil specimens of Australopithecus afarensis to Homo neanderthalensis, from 3.1 million years ago to up to 30,000 years ago, respectively [Marino, 2000]. Modern great apes and some monkeys possess EQs of 1.5 to 3.0 [Marino, 1998].

Several modern species of the cetacean suborder Odontoceti have achieved EQ levels close to 4.5 [Marino, 1998]. The encephalization levels of these dolphin and porpoise species are second only to modern humans [Marino, 1998], significantly greater than all other mammals (including living nonhuman primates) [Marino, 1998], and not significantly different than the estimated encephalization level for the fairly recent extinct hominid Homo habilis [Marino, 2000]. Figure 3 displays the encephalization levels achieved by several modern cetacean species compared with those for several modern primate species.

Modern humans possess the highest level of encephalization of all mammals. With an EQ of 7.0 our brains are seven times the size one would expect for a mammal of our body size. This high degree of encephalization appears to be the result of a rapid evolutionary process that has occurred primarily in the past three million years [Tobias, 1971; Godfrey and Jacobs, 1981; Holloway, 1983; Kappelman, 1996]. This recent dramatic increase in encephalization has been considered a potentially salient feature of the evolution of human intelligence because it suggests that there may have been very strong selection pressures for greater encephalization levels in hominids in the past few million years. Evidence that shows a similarly paced encephalization trend in a phylogenetically distant group, such as the cetaceans, would shed light on the exceptional nature of this temporal feature of human brain evolution. Although we are currently hindered by a relative lack of data on encephalization levels for both primate and especially cetacean fossil species, it is possible that cetaceans also underwent a rapid increase in encephalization level, similar to hominids, during their evolution. Some supportive clues to this hypothesis come from the 
finding that encephalization levels of Eocene archaeocetes were relatively low [Marino et al., 2000]. This finding narrows the time window within which significant increases in encephalization in cetaceans would have occurred, i.e., in the last thirty-five million years. Further data will provide an increasingly precise delineation of cetacean encephalization patterns and allow for better specificity concerning the time window and thus temporal dimensions of this process.

Fig. 3. Encephalization levels achieved by several modern cetacean species compared with those for several modern primate species. EQ = Encephalization Quotient.

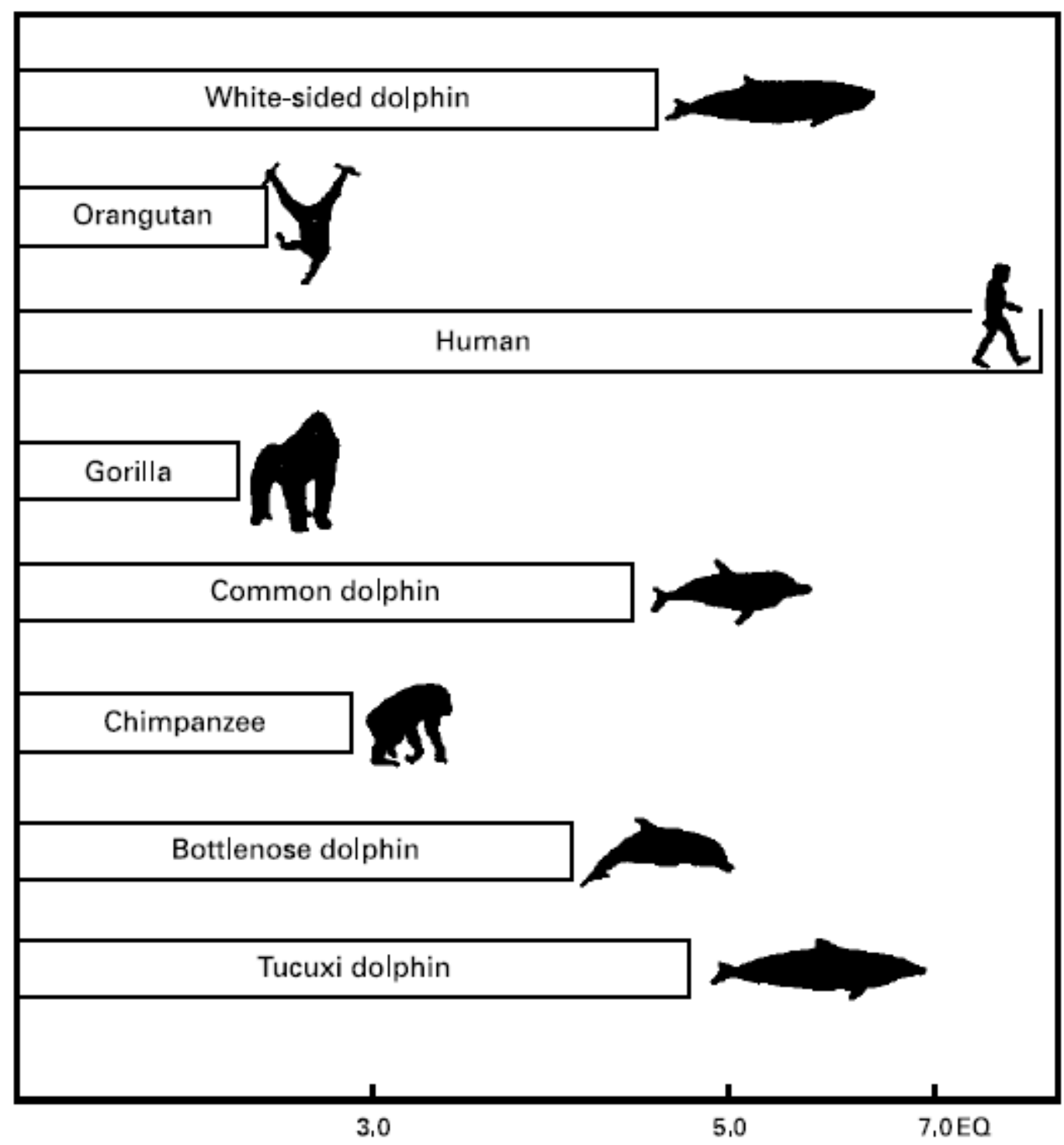

\section{Behavioral and Cognitive Convergence}

Cetaceans and primates share a number of complex behavioral and cognitive capacities and tendencies that might be unexpected on the basis of their deep phylogenetic divergence, adaptation to very different physical environments, and disparate neuroanatomical evolution. In some of these cases cetaceans exhibit behaviors and abilities not found outside of the human species or found only in great apes. This does not imply that there are no other interesting and important behavioral and cognitive parallels 
between cetaceans and other large-brained mammals or birds, for that matter. But, so far the empirical evidence points to a striking degree of convergence between primates and cetaceans in terms of the complexity, diversity, and flexibility of behavior and cognition across many domains.

\section{Convergence in Social Behavior}

Although at face value the physical characteristics of the environments in which cetaceans and primates evolved could not be more different, the striking degree of convergence in social behavior across many primate and cetacean species betrays a higher-order parallel in the evolutionary ecosystems of cetaceans and primates. Similar patterns of social ecology between cetaceans and primates may be due to similarities in predation and resource distribution. In general, the benefits of complex social organizational patterns, such as seen in many cetaceans and primates, may have the same underlying basis in both groups.

Much attention has been paid to the notion that many primates, notably chimpanzees and humans, as well as some monkeys, live a social life of such complexity that they can be described as 'political'. The term 'chimpanzee politics', for instance, has come to refer to the complex degree of interaction and social manipulation chimpanzees express in their social lives [de Waal, 1982; Byrne and Whiten, 1998]. Chimpanzees (and certainly humans) engage in various forms of social interaction that involve cooperation, alliance formation, social maneuvering, manipulation and even deception. Increasing evidence has shown that the term 'political' could equally describe the social lives of dolphins and many other cetaceans.

Both the primate and cetacean orders are characterized by relatively long periods during which juveniles are vulnerable to predation [Connor et al., 2000b]. In addition to life history, predation pressure for instance may have contributed to convergence in spatial distribution and social behavior between primates and cetaceans. Several social dimensions that are shared between primates and cetaceans have apparently resulted in remarkable convergence in social grouping patterns, individual behaviors, and in all likelihood, the cognitive processes that underlie sociality.

Bottlenose dolphins and humpback whales (and probably other cetacean species) exhibit a fission-fusion social structure very similar to that of chimpanzees, humans and spider monkeys [Smolker et al., 1992; Connor et al., 1998, 2000a]. Fission-fusion societies are, by nature, extremely complex because they represent a constantly dynamic social situation involving the movement of different individuals into and out of groups at various times. In order to explain this similarity between some cetaceans and primates, a number of comparisons have been made between the patchy and temporally variable distribution of the main food items for primates (fruit and leaves) and cetaceans (fish, krill, and cephalopods) [Wursig, 1978].

Both male chimpanzees and bottlenose dolphins, and humans for that matter, form cooperative alliances or coalitions for the purposes of intergroup aggression ('warfare') or aggressive herding of females [Connor et al., 1992a; Wrangham and Peterson, 1996; Watts, 1998]. Bottlenose dolphins apparently form nested hierarchical levels of alliances for the purposes of coercing females within the group to mate, taking females from other alliances, and defending herded females against other groups [Connor et al., 1992b, 1999]. These nested levels of consortship and alliance formation in cetaceans have not been documented in any other species except humans.

Similar predation pressures in cetaceans and primates may underlie parallels in the spatial distribution of subgroups within social groups and the level of cooperation among various individuals in the social group. A number of primate and cetacean species are capable of complex, variable, and highly flexible 
cooperative actions. One aforementioned example is cooperative coalition formation among males. Another example is alloparental care. In many primate species females stay in close proximity to and baby-sit juveniles in the group in order to protect them from predation and other threats [Nicolson, 1986]. Alloparental care is apparently widespread among odontocetes, e.g., bottlenose dolphins [Brown and Norris, 1956; Wells, 1991] sperm whales [Whitehead, 1996] spinner dolphins [Johnson and Norris, 1994] killer whales [Haenel, 1986] and harbor porpoises [Anderson, 1969] among other species. There is evidence, for example, of cooperative baby-sitting among adult female sperm whales. Because juvenile sperm whales must remain near the surface while their mothers forage at depth, adults take turns diving when calves are present so that some adults remain near the surface to watch the calves at all times [Whitehead, 1996]. In addition to cooperative alliance formation and alloparenting, many primates and cetaceans exhibit cooperative feeding strategies that require coordinated effort on the part of groups of individuals. Examples include group hunting of monkeys by chimpanzees [Wrangham and Peterson, 1996]. In cetaceans these examples are even more widespread. They include cooperative bubble net feeding in humpback whales [Jurasz and Jurasz, 1979; Hain et al., 1982], cooperative use of the water surface to trap prey in dusky dolphins [Wursig and Wursig, 1980], cooperative 'strand feeding' by bottlenose dolphins [Leatherwood, 1975; Petricig, 1993], and numerous other examples throughout the cetacean order.

In addition to sharing specific patterns of social behavior, cetaceans and primates also share the distinction of possessing behavioral traditions that suggest these traditions are cultural. Cultural transmission of information about tool manufacturing and use, for instance, has been documented in chimpanzees [Boesch, 1996; McGrew, 1992; de Waal, 2001], Japanese macaques [Huffman, 1996] and other species. Recently, enough data has been amassed on wild cetaceans to show that many species possess cultural traditions with regard to dialects [Whitehead, 1998], tool use [i.e., sponge carrying in bottlenose dolphins; Smolker et al., 1997], methods of prey capture in killer whales [Heimlich-Boran and Heimlich-Boran, in press] and other social behaviors.

Nonhuman culture is considered a very rare occurrence and in most cases these traditions are not thought to have the stability necessary to make a significant impact on genetic evolution. However, recent studies on sperm whales have shown that this species possesses a matrilineal cultural practice that influences the genetic composition of the group [Whitehead, 1998]. Although non-primate and noncetacean species, such as some birds and elephants, may possess culture, it is relevant to the present convergence argument that in this domain, too, the strongest cases can be made with primates and cetaceans.

It is intriguing that there is some suggestion that the similarities in sociality exhibited by many primates and cetaceans are accompanied by similar relationships with brain size. A number of studies reveal a positive correlation between measures related to encephalization and social group size in primates [Sawaguchi and Kudo, 1990; Sawaguchi, 1992; Dunbar, 1992, 1993; Barton, 1996]. Although group size itself is not a direct measure of more complex aspects of social life, these findings suggest, to some authors, that social demands may have played a role in the evolution of intelligence in many primates [Barton, 1996; Dunbar, 1998]. Likewise, there is a significant positive correlation between EQ and pod size [the cetacean social unit most analogous to the level of grouping examined in primate studies; Marino, 1996]. Therefore, these findings suggest that the relationship between relative brain size and one measure of sociality, i.e., social group size, is similar in cetaceans and primates. However, much more work is needed to determine whether this relationship is consistent for more direct measures of social complexity in the two groups. 
There are few species, with perhaps the exception of the African Grey Parrot [Pepperberg, 1999] that have successfully demonstrated the ability to comprehend an artificial (i.e., human devised) communication system based upon symbols and rules, i.e., semantics and simple syntax. With the exception of the African Grey Parrot, those species that have been successful subjects in studies of artificial 'language' comprehension are all members of the primate or cetacean order, i.e. great apes and bottlenose dolphins, respectively. Only three species have shown the capacity to understand that symbol or 'word' order has meaning. This basic form of sentence comprehension has been demonstrated in a bonobo [Savage-Rumbaugh et al., 1993], a chimpanzee [Premack, 1976] and in bottlenose dolphins [Herman, 1986]. Although the comparability of primate and cetacean (as well as avian) studies of artificial 'language' comprehension must be carefully considered, it is interesting that only a very few species within these groups have been able to meaningfully participate in such studies and provide compelling, if not definitive, behaviors within the context of these studies. The fact that artificial 'language' studies can only be meaningfully attempted with these very few species suggests that these few species have converged toward a level of cognitive complexity that allows them to understand a simple but symbolic and rule-based system of communication.

\section{Convergence in Self-Recognition Ability}

The ability to recognize oneself in a mirror, or mirror self-recognition (MSR), is an exceedingly rare capability in the animal kingdom. Up until recently, MSR has been found only in humans and Pongids (great apes) [Gallup, 1970; Lethmate and Ducker, 1973; Patterson, 1984; Povinelli et al., 1993, 1997;

Patterson and Cohn, 1994; White Miles, 1994; Walraven et al., 1995] with numerous unsucapes, and elephants [Bayart and Anderson, 1985; Suarez and Gallup, 1986; Anderson and Roeder, 1989; Povinelli, 1989; Hyatt, 1998]. All of the non-Pongid species, including elephants and African Grey Parrots [Pepperberg et al., 1995] demonstrate the ability to use a mirror to mediate or guide their behavior but do not use a mirror to investigate their own bodies. The ability to use the mirror for self-investigation is a byproduct of the cognitive ability to possess a physical sense of self, or 'l', robust enough to be conceived of and mentally contemplated. In humans MSR emerges reliably at approximately eighteen to twenty months of age [Amsterdam, 1972] and marks the beginning of a developmental process of achieving increasingly abstract psychological levels of self-awareness and awareness of others, including introspection and mental state attribution [Piaget, 1952]. Knowledge of this developmental sequence in humans has spawned intriguing questions about whether other species that show MSR are also capable of these other more abstract levels of thought and awareness [Premack and Woodruff, 1978; Gallup, 1998; Povinelli, 1998].

Recently, Diana Reiss and I reported the first conclusive evidence of MSR in a nonprimate species, the bottlenose dolphin. In a series of controlled variations of the procedures used to test MSR in primates, both dolphins in our study used a mirror to investigate parts of their bodies that were marked [Reiss and Marino, 2001]. Figure 4 shows one of the dolphin subjects investigating a mark on his head using the mirror.

Prior to our study demonstrating MSR in dolphins, convincing evidence of MSR had been confined to great apes and humans. Therefore, scientific theorizing about the evolutionary basis and significance of MSR has for decades focused on characteristics of the physical environment, social ecology, cognition, and neurobiology shared by great apes and humans exclusively [Povinelli, 1993; Parker et al., 1994; Povinelli and Cant, 1995; Gallup, 1997; Byrne and Whiten, 1998]. For example, as mentioned earlier much attention has been placed on the cortical circuitry of the prefrontal cortex in humans and great apes as the neuroanatomical substrate necessary for self-recognition and other dimensions of self-awareness 
[Stuss, 1991; Keenan et al., 2000; Stuss and Alexander, 2000; Kircher et al., 2001; Miller et al., 2001; Stuss et al., 2001]. But MSR in dolphins presents a challenge to primate-centered theories of the evolution and ontogeny of self-recognition and, perhaps, more abstract levels of self-awareness. The Reiss and Marino findings show that dolphins are capable of MSR despite possession of unelaborated frontal lobes (or homologous frontal lobe structures) and a cortical organizational pattern that is very different from that of primates. Therefore, although frontal lobes may be important and even necessary for MSR and self-awareness in humans and other primates, it is apparently not the neuroanatomical basis for this capacity in cetaceans. The findings of MSR in dolphins open up the possibility that the emergence of self-recognition, and perhaps other forms of self-awareness, are not byproducts of factors unique to humans and great apes. Instead, more general factors, such as encephalization level or level of cortical connectivity, may play a role in determining whether a species is capable of such a complex abstract cognitive process as self-recognition.

Fig. 4. One of the dolphin subjects in the self-recognition study [Reiss and Marino, 2001] investigating a mark on his head using the mirror.

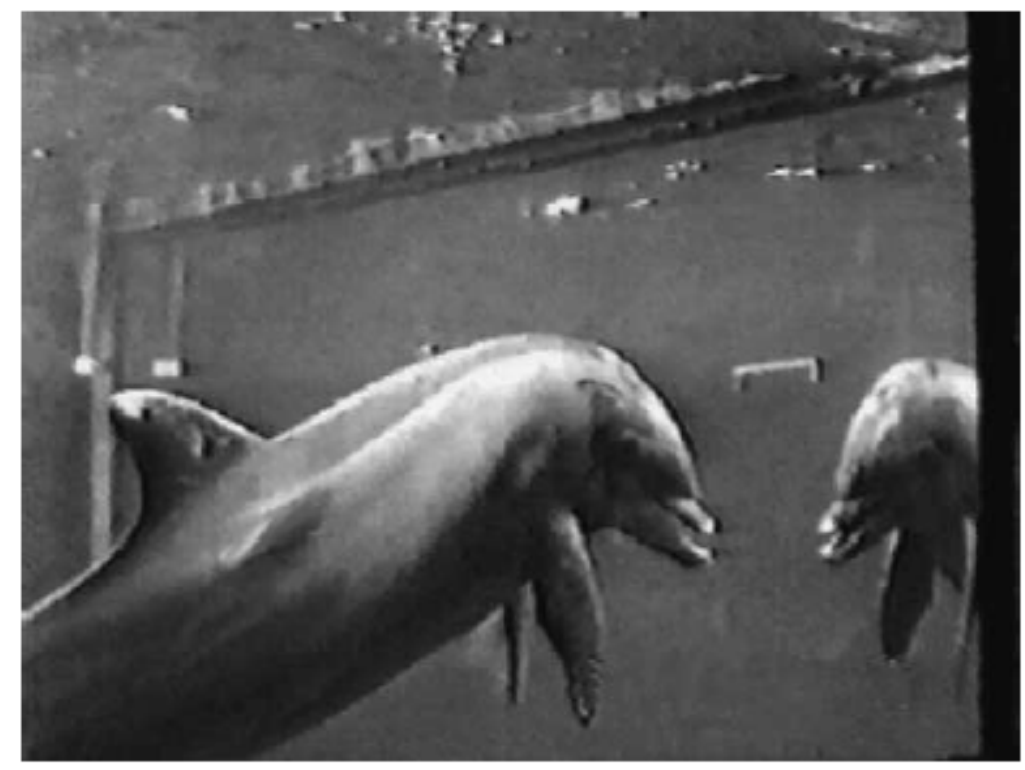

\section{Implications for the Evolution of Intelligence}

Primates and cetaceans have undergone long, separate evolutionary histories of adaptation to radically different physical environments. As a result of this evolutionary independence from each other, primates and cetaceans have evolved very different ways of increasing their brain mass. These differences represent two ways to evolve large brains. Because of these differences, however, any convergence in cognition and behavior must be due to different cortical circuitry in these two groups. Because primates and cetaceans are both mammals, they share much of their subcortical neuroanatomy. The major differences appear to be in cortical elaboration. Therefore, at some level, primate-cetacean cognitive and behavioral convergence is a dramatic example of functional convergence in the face of profound structural or mechanistic divergence.

It is striking that convergence in primates and cetaceans is observed in so many domains from social complexity to cultural transmission to manipulation of the environment to artificial language comprehension and now in the ability to possess a sense of the self, at least on the physical level. It 
remains to be seen whether primates and dolphins will show convergence at even more abstract levels of cognition, e.g., introspection, mental state attribution, deception, moral judgment, etc.

The primate-cetacean example of behavioral and cognitive convergence coupled with neuroanatomical divergence compels us to understand how and why this occurred and to consider the implications for the evolution of intelligence. Cetacean brains and primate brains represent alternative ways brains can increase in size and complexity and arrive at similar cognitive or even computational capacities. Therefore, this example implies that there may be general principles or 'rules' that underlie the evolution of intelligence and that the specific way that a given species arrives at a functional solution is not perhaps the only level at which to understand intelligence. Returning to Stephen Jay Gould's question of whether intelligence on a par with humans can emerge independently of human evolution, the primate-cetacean example takes us part of the way towards an affirmative answer to this question.

\section{References}

Allman, J.M. (1999) Evolving Brains. Scientific American Library, New York.

Amsterdam, B. (1972) Mirror self-image reactions before age two. Dev. Psychobiol., 5: 297-305.

Anderson, J.R. and J.J. Roeder (1989) Responses of capuchin monkeys (Cebus apella) to different conditions of mirror-image stimulation. Primates, 30: 581-587.

Anderson, S. (1969) Epimeletic behavior in a captive harbour porpoise, Phocoena phocoena. In Investigations on Cetacea, Vol. 1 (ed. by G. Pilleri), Brain Anatomy Institute, Berne, pp. 203- 205.

Bajpai, S., and P.D. Gingerich (1998) A new Eocene archaeocete (Mammalia, Cetacea) from India and the time of origin of whales. Proc. Of Nat. Acad. Sci., 95: 15464-15468.

Barnes, L.G., D.P. Domning, and C.E. Ray (1985) Status of studies on fossil marine mammals. Marine Mamm. Sci., 1: 15-53.

Barton, R.A. (1996) Neocortex size and behavioral ecology in primates. Proc. R. Soc. Lond. Series B Biol. Sci., 263: 173-177.

Bayart, F., and J.R. Anderson (1985) Mirror-image reactions in a tool-using adult male Macaca tonkeana. Behav. Proc., 10: 219-227.

Boesch, C. (1996) The emergence of cultures among wild chimpanzees. Proc. Brit. Acad., 88: 251-268.

Bromham, L., M.J. Phillips, and D. Penny (1999) Growing up with dinosaurs: Molecular dates and the mammalian radiation. Trends Ecol. Evol., 14: 113-118.

Brown, D.H., and K.S. Norris (1956) Observations of captive and wild cetaceans. J. Mammal., 37: 311326.

Byrne, R.W., and A. Whiten (1998) Machiavellian Intelligence: Social Expertise and the Evolution of Intellect in Monkeys, Apes, and Humans. Clarendon, Oxford, UK.

Connor, R.C., M.R., Heithaus, and L.M. Barre (1999) Superalliance of bottlenose dolphins. Nature, 397: 571-572.

Connor, R.C., J. Mann, P.L. Tyack, and H. Whitehead (1998) Social evolution in toothed whales. Trends Ecol. Evol., 13: 228-232. 
Connor, R.C., A.J. Read, and R. Wrangham (2000b) Male reproductive strategies and social bonds. In Cetacean Societies: Field Studies of Dolphins and Whales (ed. by J. Mann, R.C. Connor, P.L. Tyack and H. Whitehead), University of Chicago Press, Chicago, IL, pp. 247-269.

Connor, R.C., R.A. Smolker, and A.F. Richards (1992a) Dolphin alliances and coalitions. In Coalitions and Alliances in Humans and Other Animals (ed. by A. H. Harcourt and F.B.M. de Waal), Oxford University Press, Oxford, UK, pp. 415-443.

Connor, R.C., R.A. Smolker, and A.F. Richards (1992b) Two levels of alliance formation among bottlenose dolphins (Tursiops sp.). Proc. Natl. Acad. Sci. USA, 89: 987-990.

Connor, R.C., R.S. Wells, J. Mann, and A.J. Read (2000a) The bottlenose dolphin: social relationships in a fission-fusion society. In Cetacean Societies: Field Studies of Dolphins and Whales (ed. by J. Mann, R.C. Connor, P.L. Tyack and H. Whitehead), University of Chicago Press, Chicago, IL, pp. 91-126.

Cooper, J.D., R.H. Miller, and J. Patterson (1990) A Trip Through Time: Principles of Historical Geology. Merrill Pub. Co., Columbus, $\mathrm{OH}$.

Davis, J. (1997) Mapping The Brain. Birch Lane Press, Secaucus, NJ. de Waal, F.B.M. (1982) Chimpanzee Politics: Power and Sex Among Apes. Johnathan Cape, London. de Waal, F.B.M. (2001) The Ape and The Sushimaster. Basic Books, New York.

Dunbar, R.I.M. (1992) Neocortex size as a constraint on group size in primates. J. Human Evol., 20: 469493.

Dunbar, R.I.M (1993) Coevolution of neocortical size, group size and language in humans. Behav Brain Sci., 16: 681-735.

Dunbar, R.I.M. (1998) The social brain hypothesis. Evol. Anthropol., 6: 178-190.

Fleagle, J.G. (1988) Primate Adaptation and Evolution. Academic Press, San Diego, CA.

Fordyce, R.E., and L.G. Barnes (1994) The evolutionary history of whales and dolphins. Ann. Rev. Earth Planet. Sci., 22: 419-455.

Gallup, G.G., Jr. (1970) Chimpanzees: Self recognition. Science, 167: 86-87.

Gallup, G.G., Jr. (1997) On the rise and fall of selfconception in primates. Ann. New York Acad. Sci., 818: 73-84.

Gallup, G.G., Jr. (1998) Can animals empathize? Sci. Am., 9: 66-71.

Garey, L.J., and G. Leuba (1986) A quantitative study of neuronal and glial numerical density in the visual cortex of the bottlenose dolphin: Evidence for a specialized subarea and changes with age. J. Comp. Neurol., 247: 491-496.

Garey, L.J., E. Winkelman, and K. Brauer (1985) Golgi and Nissl studies of the visual cortex of the bottlenose dolphin. J. Comp. Neurol., 240: 305-321.

Glezer, I.I., M. Jacobs, and P. Morgane (1988) Implications of the 'initial brain' concept for brain evolution in Cetacea. Behav. Brain. Sci., 11: 75-116. 
Godfrey, L., and K.H. Jacobs (1981). Gradual, autocatalytic, and punctuational models of hominid brain evolution: a cautionary tale. J. Human Evol., 10: 255-272.

Gould, S.J. (1983) The wisdom of Casey Stengel. Discover, March: 62-65.

Grossman, M., and M. Desposito (1996) The physiological basis of executive function and working memory. Neuroscience 2: 345-352.

Haenel, N. J. (1986) General notes on the behavioral ontogeny of Puget Sound killer whales and the occurrence of allomaternal behavior. In Behavioral Biology of Killer Whales (ed. by B. Kirkevold and J. S Lockard), Alan R. Liss, New York, pp. 285-300.

Hain, J.H.W., G.R. Cater, S.D. Kraus, C.A. Mayo, and H.E. Winn (1982) Feeding behaviour of the humpback whale, Megaptera novaengliae, in the western North Atlantic. Fish. Bull., 80: 259-268.

Heimlich-Boran, J.R., and S.L. Heimlich-Boran (in press). Social learning in cetaceans: hunting, hearing and hierarchies. Symp. Zool. Soc. Lond., 73.

Herman, L.M. (1986) Cognition and language competencies of bottlenosed dolphins. In Dolphin Cognition and Behavior: A Comparative Approach (ed. by R. J. Schusterman, J.A. Thomas and F.G. Wood), Lawrence Erlbaum, Mahwah, NJ, pp. 221-252.

Holloway, R.L. (1983) Human brain evolution: a search for units, models and synthesis. Can. J. Anthropol., 3: 215-230.

Huffman, M.A. (1996) Acquisition of innovative cultural behaviors in non-human primates: A case study of stone handling, a socially transmitted behavior in Japanese macaques. In Social Learning in Animals: The Roots of Culture, (ed. by C.M. Heyes and B.G. Galef), Academic Press, New York, pp. 267-289.

Hyatt, C.W. (1998) Responses of gibbons (Hylobates lar) to their mirror images. Am. J. Primatol., 45:30311.

Jerison, H.J. (1973) Evolution of the Brain and Intelligence. Academic Press, New York.

Johnson, C.M., and K.S. Norris (1994) Social Behavior. In The Hawaiian Spinner Dolphin (ed. by K.S. Norris, B. Wursig, R.S. Wells and M. Wursig), University of California Press, Berkeley, CA, pp. 243-286.

Jurasz, C.M., and V.P. Jurasc (1979) Feeding modes of the humpback whale, Megaptera novaengliae, in southeast Alaska. Sci. Rep. Whales Res. Inst. Tokyo, 31: 69-83.

Kandel, E.R., J.H. Schwartz, and T.M. Jessell (1991) Principles of Neural Science. McGraw-Hill, New York.

Kappelman, J. (1996) The evolution of body mass and relative brain size in fossil hominids. J. Human Evol., 30: 243-276.

Keenan, J.P., M. Wheeler, G.G. Gallup, Jr., and A. Pascual-Leone (2000) Self-awareness and the right prefrontal cortex. Trends Cog. Sci., 4: 338-344. 
Kircher, T.T.J., C. Senior, M.L. Phillips, S. Rabe-Hesketh, P.J. Benson, E.T. Bullmore, M. Brammer, A. Simmons, M. Bartels, and A.D. David (2001) Recognizing one's own face. Cognition, 78: B1B15.

Ladygina, T.F., A.M. Mass, and A.Ya. Supin (1978) Multiple sensory projections in the dolphin cerebral cortex. Zh. Vyssh. Nerv.Deiat., 28: 1047-1054.

Leatherwood, S. (1975) Some observations of feeding behavior of bottlenosed dolphins (Tursiops truncatus) in the northern Gulf of Mexico and (Tursiops gilli) off southern California, Baja, California, and Nayarit, Mexico. Mar. Fish. Rev., 37: 10-16.

Lethmate, J., and G. Ducker (1973) Self-recognition by orangutans and some other primates. Z. Tierpsychol., 33: 248-269.

Marino, L. (1996) What can dolphins tell us about primate evolution? Evol. Anthropol., 5: 81-85.

Marino, L. (1998) A comparison of encephalization between odontocete cetaceans and anthropoid primates. Brain Behav. Evol., 51: 230-238.

Marino, L. (2000) Turning the empirical corner on Fi: the probability of complex intelligence. In Bioastronomy '99: A New Era in Bioastronomy (ed. by G. Lemarchand and K.J. Meech), Astronom. Soc. Pacific, San Francisco, CA, pp. 431-435.

Marino, L., M.D. Uhen, B. Frohlich, J.M. Aldag, C. Blane, D. Bohaska, and F.C. Whitmore, Jr., (2000) Endocranial volume of mid-late Eocene archaeocetes (Order: Cetacea) revealed by computed tomography: implications for cetacean brain evolution . J. Mamm. Evol., 7: 81-94.

McGrew, W.C. (1992) Chimpanzee material culture: Implications for human evolution. Cambridge University Press, Cambridge, UK.

Miller, B.L., W.W. Seeley, P. Mychack, H.J. Rosen, I. Mena, and K. Boone (2001) Neuroanatomy of the self-evidence from patients from frontotemporal dementia. Neurology, 57: 817-821.

Morgane P. J., M.S. Jacobs, and W.L. MacFarland (1980) The anatomy of the brain of the bottlenose dolphin (Tursiops truncatus). Surface configurations of the telencephalon of the bottlenose dolphin with comparative anatomical observations in four other cetacean species. Brain Res. Bull., 5: 1-107.

Mukhametov, L.M. (1984) Sleep in marine mammals. Exper. Brain Res. Suppl., 8: 227-238.

Napier, J., and P. Napier (1985) The Natural History of the Primates. MIT Press, Cambridge, MA.

Nicolson, N.A. (1986) Infants, mothers, and other females. In Primate Societies (ed. by B.B. Smuts, D.L. Cheney, R.M. Seyfarth, R.W. Wrangham and T.T. Struhsaker), University of Chicago Press, Chicago, IL, pp. 330-342.

Parker, S.T., R.W. Mitchell, and M.L. Boccia (1994) Self-awareness in Animals and Humans: Developmental Perspectives, Cambridge University Press, Cambridge, UK.

Patterson F.G. (1984) Self-recognition by Gorilla (Gorilla gorilla gorilla). (Newsletter published by The Gorilla Foundation), 7: 2-3. 
Patterson, F.G., and R.H. Cohn (1994) Self-recognition and self-awareness in lowland gorillas. In Selfawareness in Animals and Humans: Developmental Perspectives (ed. by S.T. Parker, R.W. Mitchell and M.L. Boccia), Cambridge University Press, Cambridge, UK, pp. 273-290.

Peichl, L., G. Behrmann, and R.H. Kroger (2001) For whales and seals the ocean is not blue: a visual pigment loss in marine mammals. Eur. J. Neurosci., 13: 1520-1528.

Pepperberg, I.M. (1999) The Alex Studies. Harvard University Press, Cambridge, MA.

Pepperberg, I.M., S.E. Garcia, E.C. Jackson, and S. Marconi (1995) Mirror use by African Grey Parrots (Psittacus erithacus). J. Comp. Psychol., 109: 182-195.

Petricig, R.O. (1993) Diel patterns of strand-feeding behavior by bottlenose dolphins in South Carolina salt marshes. Abstract in Tenth Biennial Conference on the Biology of Marine Mammals, Galveston, TX.

Piaget, J. (1952) The Origins of Intelligence in Children. Norton, New York.

Popov, V.V., T.F. Ladygina, and A.Ya. Supin (1986) Evoked potentials of the auditory cortex of the porpoise, Phocoena phocoena. J. Comp. Physiol., 158: 705-711.

Povinelli, D.J. (1989) Failure to find self-recognition in Asian elephants (Elephas maximus) in contrast to their use of mirror cues to discover hidden food. J. Comp. Psychol., 103: 122-131.

Povinelli, D.J. (1993) Reconstructing the evolution of mind. Am. Psychol., 48: 493-509.

Povinelli, D.J. (1998) Can animals empathize? Sci. Am., 9: 67-75.

Povinelli, D.J., and J.G.H. Cant (1995) Arboreal clambering and the evolution of self-conception. Quart. Rev. Bio., 70: 393-421.

Povinelli, D.J., G.G. Gallup Jr., T.J. Eddy, D.T. Bierschwale, M.C. Engstrom, H.K. Perilloux, and I.B. Toxopeus (1997) Chimpanzees recognize themselves in mirrors. Anim. Behav., 53: 1083-1088.

Povinelli, D.J., A.B. Rulf, K. Landau, and D.T. Bierschwale (1993) Self-recognition in chimpanzees (Pan troglodytes): distribution, ontogeny and patterns of emergence. J. Comp. Psychol., 107: 347-372.

Premack, D. (1976) Intelligence in Ape and Man. Lawrence Erlbaum Assoc., Mahwah, NJ.

Premack, D., and G. Woodruff (1978) Does the chimpanzee have a theory of mind? Behav. Brain. Sci., 1: 515-526.

Reiss, D., and L. Marino (2001) Mirror self recognition in the bottlenose dolphin: a case of cognitive convergence. Proc. Nat. Acad. Sci., 98: 5937-5942.

Ridgway, S.H. (1990) The central nervous system of the bottlenose dolphin. In The Bottlenose Dolphin (ed. by S. Leatherwood and R. Reeves), Academic Press, San Diego CA, pp. 69-97.

Ridley, M. (1993) Evolution. Blackwell Scientific Publications, Inc., Oxford, UK.

Rowe, A.D., P.R. Bullock, C.E. Polkey, and R.G. Morris (2001) 'Theory of mind' impairments and their relationship to executive functioning following frontal lobe excisions. Brain, 124: 600-616. 
Savage-Rumbaugh, E.S., J. Murphy, R.A. Sevcik, K. Brakke, S. Williams, and D.M. Rumbaugh (1993) Language comprehension in ape and child. Mono. Soc. Res. Child Devel. Ser. No. 233, Vol. 58, Nos. 3-4.

Sawaguchi, T. (1992) The size of the neocortex in relation to ecology and social-structure in monkeys and apes. Folia Primat., 58: 131-145. 